\title{
A Study On HR Practices In CVRCE
}

\author{
Dr.B.Archana ${ }^{1}$ and Prof.M.S.Bhat ${ }^{2}$ \\ ${ }^{1}$ CVR College of Engineering, Department of M.S., Ibrahimpatan, R.R.District, A.P., India \\ Email: archana_boda@yahoo.co.in \\ ${ }^{2}$ CVR College of Engineering, Department of M.S., Ibrahimpatan, R.R.District, A.P., India \\ Email: bhatmas@rediff.com
}

\begin{abstract}
The studies on Human Resource Practices are positively linked with employee performance and institutional performance in the education sector. On this perspective, this study examines the various HR practices based on the survey of the selected teaching employees of CVRCE. The results of the study indicate a high degree of satisfaction by the employees towards the various HR practices being followed by the institution.
\end{abstract}

Index Terms-HR Practices, Selected Teaching Employees, CVRCE.

\section{INTRODUCTION}

CVR College of Engineering (CVRCE), approved by AICTE and affiliated to JNT University, Hyderabad was established in 2001. It was ranked in the TOP-8 among all colleges in Osmania University (OU) area during EAMCET-2008 counseling. It was also ranked as the \#1 college among more than 420 colleges in Andhra Pradesh that started in the last decade. It is promoted by NRI Technology Professionals, who were residents in the US.

It is the expectation of its academic community that it is on the successful path to be in the TOP-5 amongst all colleges in OU area in the next couple of years. The vision statement of CVRCE is to become a premier educational institution in India, offering the best technical training inputs to its students. It is the only Engineering college in entire Andhra Pradesh to have achieved the following three major accomplishments within the first 6 years of existence - getting NBA accreditation, having record campus placements and getting funding of $>$ Rs.18 lakhs from central government agency. To add a feather to its cap, it has Professors who have previously worked at OU and JNTU.

'Human Resources' is a terminology used to describe the individuals who make up the workforce of an institution. It is also the name of the function within an institution charged with the overall responsibility for implementing strategies and policies relating to the management of individuals, (i.e., the human resources). This function's title is often abbreviated to the initials 'HR'. In other words,

Human means the people, who are working in the organisation, Resources means the various facilities available in the organisation and Management means getting things done by others.

\section{REVIEW OF LITERATURE}

A number of researchers have reported that HR practices are positively linked with organisational and employee performance (Guest [1] 2002; Gould-Williams [2], 2003; Harley [3] 2002; Park et al [4], 2003; Wright et al [5], 2003 and Tessema [6] 2006). These researchers focused their studies in the developing countries like India, which are considered to be 'Knowledge Societies', equipped with a suitable workforce. Hence, the focus is growing on the importance of quality education delivery, which is done through efficient employees of an efficient organisation. In this context what matters most is to what extent the educational institution facilitates its employees in providing a quality education. In this backdrop, this study makes an attempt to identify the various HR Practices provided by the institution (i.e., CVRCE) 7 to its selected employees who are into teaching.

\section{OBJECTIVES}

- To understand the demographics of the selected teaching employees

- To identify the employees' perception on performance

- To identify the various factors related to compensation practices

- To identify the various factors related to performance evaluation practices

- To identify the various factors considered for promotion practices

- To identify the various factors related to turnover practices

- To rank the various welfare practices offered 
- To rank the various opportunities provided for career advancement

- To analyse the overall assessment of HR practices

\section{LIMITATIONS}

- The study was restricted only to the employees who were in teaching. Thus, omitting the non-teaching employees, who were also associated with the institution from past many years.

- The teaching employees who had not completed two and above years of service were purposefully excluded for the study.

\section{METHODOLOGY}

The various employees who were into teaching from various departments and those who have completed two and above years of their service from the same institution have been selected for the purpose of the study. However, the study is not census based and is purely on the basis of Judgmental sampling method. The selected teaching employees were from various strata like Professors, Associate Professors, Senior Assistant Professors and Assistant Professors of all the departments of the institution.

\section{DATA COLleCtion}

The Primary data was collected through personally administered structured questionnaires. The questionnaires were tested through a pilot survey about the consistency and other measures. A total of 70 questionnaires were administered to all the selected teaching employees. However, only 50 of them were received back, thus making the response rate to be $71 \%$ which was a sufficient sample size for analysis. The breakup of the responses based upon various departments to which the selected teaching employees belonged to was: ECE (14), EEE (4), CSE (3), IT (9), EIE (5), H\&S (6), MBA (4) and MCA (5).

For the purpose of data collection, the questionnaire was categorized into nine sections titled as: Demographics, Employee perception on performance, Compensation practices, Performance evaluation practices, Promotion practices, Turnover practices, Welfare practices, Opportunities for career advancement and Overall assessment of HR practices; in all containing 35 Questions. Most of the responses were marked by the selected teaching employees on a five point Likert's Scale (with endpoints: 1-
Strongly disagree, 5-Strongly agree) and few of the responses were obtained through open ended questions. For the purpose of the analysis of the data, the responses on the scale against the grades 'Agree' and 'Strongly agree' were clubbed up and the responses obtained under the grades 'Disagree' and 'Strongly disagree' were separately clubbed up. However, the responses obtained against the grade 'Neutral' are shown without any such clubbing. The required secondary data was collected from the website, brochures, newsletters and service manual of CVRCE, which was used for framing the objectives and designing the questionnaire for the purpose of the study.

\section{FINDINGS}

\section{Objective 1}

To understand the demographics of the selected teaching employees.

TABLE I:

DEMOGRAPHICS

\begin{tabular}{|c|c|}
\hline Gender & No. of employees \\
\hline Male & 25 \\
\hline Female & 25 \\
\hline Designation & No. of employees \\
\hline Assistant Professor & 34 \\
\hline Sr. Asst. Professor & 1 \\
\hline Associate Professor & 11 \\
\hline Professor & 4 \\
\hline Tenure of employment & No. of employees \\
\hline 2 years & 4 \\
\hline $2-4$ years & 14 \\
\hline 4-6 years & 21 \\
\hline More than 6 years & 11 \\
\hline Age group & No. of employees \\
\hline $20-30$ years & 14 \\
\hline $31-40$ years & 28 \\
\hline $41-50$ years & 4 \\
\hline Above 51 years & 4 \\
\hline Qualification & No. of employees \\
\hline Bachelors & 11 \\
\hline Masters & 31 \\
\hline M.Phil / MS & 7 \\
\hline Doctorate & 1 \\
\hline Mother tongue & No. of employees \\
\hline Telugu & 36 \\
\hline Hindi & 2 \\
\hline Others & 12 \\
\hline
\end{tabular}

Source: Questionnaire to the employees

- The objective of Table 1 is to show the composition of the demographics of the respondents considered for the study. As depicted above, male and female teaching employees were 25 each. Majority of them were in the strata of Assistant Professor; were falling in the tenure period of 4-6 years; were in the age group of 31-40 years; were holding Masters Degree as their qualification 
and most of theirs Mother tongue was Telugu.

\section{Objective 2}

To identify the 'employees' perception on performance.

- The selected teaching employees were requested to opine about various factors related to the perceptions of their Performances. For which, 37 of them have opined to have better performances than their colleagues with similar qualifications, 11 of them viewed to be average and only 2 of them had disagreed to it.

- 42 of them were satisfied with their performances.

- 19 of them have agreed for further improvements with their performances to be in par with other colleagues with similar qualifications. Where as, 17 of them have disagreed to it and 12 of them viewed to be average.

- However, 44 of them have agreed to the perception that their performances were better than that of the employees of the other institutions.

- It was also inferred that, 37 of them have agreed that the job in this institution is more challenging than their previous jobs in other institutions.

Objective 3

To identify the various factors related to compensation practices

- The selected teaching employees were requested to share their views on various factors related to the Compensation practices. Against which, 35 of them had agreed about the presence of an attractive compensation system. However, 15 of them expressed an average opinion about it.

- 22 of them have agreed that the salaries they received reflected their respective performances. Nevertheless, 19 of them perceived it to be average.

- Also, 36 of them opined that their salaries reflected their respective qualifications. 14 of them had average views about it.

- 33 of them remarked that other compensatory factors like incentives, etc, motivated their performances.

- The presence of equity and fairness in administering compensation was agreed by 28 of them where as 17 of them had an average opinion.

- All of them have agreed that timeliness and regularity was maintained in administering salaries and other financial benefits.

- 28 of them considered their salaries to be in compatible with the salaries of the other institutions and to be on par with the market rates.

\section{Objective 4}

To identify the various factors related to performance evaluation practices.

- The selected teaching employees were requested to comment on various factors related to performance evaluation practices. Against which, 23 of them had agreed that the performance evaluation practices were related to their salaries where as 21 of them had an average stand about it.

- 38 of them perceived that the performance evaluation practices induced them to perform better.

- With regard to whether the feedback on the performance evaluation was being communicated back to them, only 18 of them had agreed to it and 23 of them had not agreed to it. Moreover, 8 of them had an average view about it.

- 39 of them had agreed that the performance evaluation was considered to be an important task by their superiors.

- The performance evaluation factors had resulted into better performances for 23 of them; which further enabled them to know about their strengths and made them to reinforce the same. For the other 10, it resulted in making them realize about their weaknesses and enabled them to overcome the same. On the other hand, 7 of them felt that it hardly had any impact on them.

- 30 of them felt that the present performance evaluation system needed major changes to be done. Where as, 17 of them were not recommending any changes in it.

- Those who felt that a few changes in the performance evaluation system were to be done, requested the following factors to be considered in future:

- It should be transparent and should have a multilayer measures for evaluation of performances. 
- Feedback from the students, who have obtained above $70 \%$ of aggregate results, should only be taken into consideration.

- If a teacher is likely to be strict with the students, then the chances of getting a low feedback are high.

- The feedback forms given to the students must have more clarity and if possible the set of statements in the present feedback form may be revised.

- The performance evaluations should also be obtained from the HoDs concerned.

- Performances of teachers in other competitive exams like FET, Net, Gate, etc., should also be taken into consideration.

- The teachers with high and positive feedback are to be appreciated.

- Feedback obtained from the students should be communicated back to the teachers concerned.

- Maintenance of absolute confidentiality in collecting and analyzing the feedback taken from the students, to be practiced.

\section{Objective 5}

To identify the various factors considered for promotion practices.

- The selected teaching employees were requested to remark on various factors considered against promotion practices. For which, 34 of them have agreed that the aspect of seniority was considered for taking a promotion decision.

- $\quad 36$ of them remarked that performances of the employees were considered for taking a promotion decision.

- And 43 of them felt that for taking a promotion decision, only up-gradation of qualification was considered.

\section{Objective 6}

To identify the various factors related to turnover practices.

- The selected teaching employees had considered various factors that were responsible for the turnover in the institution. Relatively, 38 of them felt that employee getting a better opportunity was the main reason for the turnover. However, 8 of them felt that employees' spouse getting relocated could be one other reason. 12 of them also felt that there could be several other reasons supporting the same.
- A few suggestions as follows were given by them for having a better separation process.

- To conduct an exit interview

- If the employee quitting is able to replace another employee in the vacancy so created, then the separation process can be immediately considered

- Employees leaving the institution with a sweet note are likely to act as ambassadors in spreading a good word of mouth.

- Consideration of the loyalty and the contributions made by the employee during his/her service especially while quitting.

- For arriving at zero or low employee turnover rate, the following suggestions were also made by them.

- Identification of additional skills in the employees.

- Incentives for long time services.

- Number of casual leaves to be increased for women employees

- Employee retention to be increased

- Provision of residential campus facility for the employees

- Provision of medical leaves, sick leaves, etc

- Introduction of schemes like ESI, PPF, etc, which benefits the employees.

\section{Objective 7}

To rank the various welfare practices offered.

- Various welfare practices like having a health centre, recreation facilities, benefits for maternity issues, consideration of major sickness, crèche facilities, factors related to hygiene and cleanliness, transportation facilities, provision of personal loans, benefit of insurance cover, canteen facilities, and provision of drinks like coffee, tea, etc were rated by the selected teaching employees.

- For the purpose of analysis, aggregate of all the corresponding welfare practices was considered and averages for the same were derived with. The result states that majority of these practices which were numbering to 26 were considered to be followed on a highly satisfactory level. Only 11 of them were marked them as less satisfied practices. However, 10 of them were marked as being practiced on an average basis. 


\section{Objective 8}

To rank the various opportunities provided for career advancement.

- The selected teaching employees ranked the various opportunities available to them for career advancement. A tremendous response by 48 of them was received in favor of its encouragement. However, only 2 of them opined that, they were not aware of such practices being followed.

- The various opportunities that were provided for career advancement were listed out for ranking. For the purpose of analysis, the corresponding ranks against various opportunities mentioned in the questionnaire were aggregated and their averages were derived. Out of which, 33 of them were highly ranked and only 9 of them were ranked as being provided on less satisfactory terms.

\section{Objective 9}

To analyse the overall assessment of HR practices.

- The selected teaching employees were requested to assess the overall HR practices being followed in the institution. For which, they were asked to indicate a rank on a scale of 1-9, where, 1 represented low rank and 9 represented high rank. Against which, 5 of them had indicated their overall assessment by ranking ' 9 ', 8 of them ranked it as ' 8 ', 11 of them ranked it as ' 7 ' and 10 of them ranked it as ' 5 '.

- For yet another statement, whether the present job has explored their potentialities to the full extent, 30 of them had agreed to it. However, very few of them had the following suggestions to be made in this regard.

- Additional potentialities of the employees are to be identified and can be used effectively.

- Employees pursuing Ph.D require guidance from the experts within the institution.

- Pay slips in respect to the salaries deposited are to be given every month to the employees.

- Identify the students who would like to excel in academics and provide extra support to them with the assistance of the expert teachers.

\section{TESTING OF HyPOTHESIS}

It is proposed to formulate and test the following two hypotheses.

The individual score of assessment has been obtained using 9 point scale and one way ANOVA, a parametric analysis is considered to be appropriate for formulating and testing the following hypothesis. Among the 50 selected teaching employees approached, 6 of them had not responded against this, and the same is being omitted.

A. 8.1 Null Hypothesis: There is no difference in mean scores on overall assessment of HR practices at CVRCE among four groups of selected teaching employees of various tenures. Alternate Hypothesis: There is difference in mean scores on overall assessment of HR practices at CVRCE among four groups of selected teaching employees of various tenures.

Interpretation: On performing the, ANOVA at degrees of freedom being 3 for the numerator (value is 0.44 ) and 40 for the denominator (value is 6.39), at Level of significance of $95 \%$, the calculated value obtained for $\mathrm{F}$ is 0.06 and the table value obtained for $\mathrm{F}$ is 8.59. As the calculated value is lesser than the table value, Null Hypothesis is accepted and so it is inferred that the overall score among the groups with varying tenures do not differ significantly.

8.2 Null Hypothesis: Less than 50\% of the employees at CVRCE perceive that their current job explores their potential in full through the present HR practices.

Alternate Hypothesis: More than 50\% of the employees at CVRCE perceive that their current job explores their potential in full through the present HR practices.

For the purpose of testing the above hypothesis, $\mathrm{z}$ test was used at the significance level of $95 \%$.

$$
\mathrm{Z}=\left(\mathrm{p}_{1}-\mathrm{p}_{2}\right) / \mathrm{SE}
$$

Where; $\mathrm{p}_{1(0.60)}$ is Sample proportion, $\mathrm{p}_{2}(0.50)$ is Hypothesis proportion and SE (0.022) is the Standard error of the sampling distribution.

Interpretation: $\mathrm{By}$ applying the $\mathrm{Z}$ test, the calculated value is 4.54 and the table value obtained is 1.64. Since calculated value is more than the table value, Null Hypothesis is rejected and it can be empirically concluded that more than $50 \%$ of the employees at CVRCE perceive that their current job explores their potential in full through the present HR practices. 


\section{SUGGestions AND CONCLUSIONS}

The HR practices have a direct impact on the employees of any educational institution. These practices not only help the employees to grow in an institutional stratum, but also serve as a mode for effective and qualitative teaching. Although, most of the HR practices were well appreciated by the selected teaching employees, it was also found that there were some lacunae, which are yet to be identified and improved for further enhancement of the quality of HR practices.

The primary data collected from the study has proved that the selected teaching employees of CVRCE were contented with the various HR practices provided to them and its subsequent impact was also obvious from the various achievements of CVRCE as inferred from the secondary data. The statistical tools applied to various assumptions made in the study, empirically concluded that the tenure of the employees has impact on the perception of overall assessment of HR practices at CVRCE and it was also concluded that more than $50 \%$ of the employees at CVRCE perceive that their current job explores their potential in full through the present HR practices.

In a nutshell, HR practices, in the cause of education especially by an educational institution are imperative for the pursuit of excellence and also for building up wise and skilled citizens of a nation.

\section{SCOPE FOR FURTHER STUDY}

The measurement of HR practices followed by an institution is a continuous process. Also, in the context of enhancing and improving the HR practices in future and with greater chances of further increase in the size of the teaching employees in the years ahead, there is a scope to conduct similar study over a period of time.

\section{ACKNOWLEDGEMENT}

At the outset we wish to express our sincere gratitude to the Management without whose kind approval this study titled 'HR Practices at CVRCE' would have never been possible. The institutionalisation of good HR practices commenced with the former Principal, Dr. Rama Sastry, our present Director. We also thank our Principal Dr. A.D. Rajkumar, for his kind consideration in providing me an opportunity to carry out the same. We also take this opportunity in thanking all the teaching staff of the Department of Management Studies who contributed with their valuable suggestions during the Pilot survey. We also would like to thank all the respondents of the study for their kind cooperation, keen interest and timely submission of the filled-in questionnaires. Our sense of gratitude is conveyed in a special way to all the Heads and Professors of various departments who were also part of the respondents. We also owe our gratitude to Ms. Harini, DTP operator, for rendering her assistance in making the Questionnaires available in the form of softcopy.

\section{REFERENCES}

[1] Guest, D (2002). Human Resource Management, Corporate Performance and Employee Wellbeing: Building the Worker into HRM, the Journal of Industrial Relations, 44(3), 335-358.

[2] Gould-Williams, J. (2003). The importance of HR practices a workplace trust in achieving superior performance: A study of public sector institutions, International Journal of Human Resource Management, 14(1), 28-54.

[3] Harley, B (2002). Employee Responses to High Work Performance System Practices, the Journal of Industrial Relations, 44(3), 418-434.

[4] Park, H. J. Mitsuhashi, H.Fey, C.F.Bjorkman, I. (2003). The effect of human resource management practices on Japanese MNC subsidiary performance, 14(8), 1391-1406.

[5] Wright, P.M.Garden, T.M, T.M. and Moynihan, L.M. (2003). The impact of HR practices on the performance of business units, Human Resource Management Journal, 13 (3), 21-36.

[6] Tessema, $M$ and Soeters, J (2006). Challenges and prospects of HRM in developing countries: International Journal of Human Resource Management, 17(1), 86105.

[7] http://cvr.ac.in

[8] News letters, Brochures and Service manual of CVRCE. 